\title{
Study of Complex Mineral Fertilizers on the Basis of a Technogenic Wastes of Phosphorus Production
}

\author{
U.B. NAZARBEK ${ }^{\star 1}$, U. BESTEREKOV S.P'. NAZARBEKOVA², \\ O BEISENBAYEV ${ }^{1}$ and A BOLYSBEK ${ }^{1}$ \\ 'Department of Chemical Technology of Inorganic Substances, \\ 2Department of Chemistry, M.Auezov South Kazakhstan State University, \\ South-Kazakhstan region, Kazakhstan \\ *Corresponding author E-mail: unazarbek@mail.ru
}

http://dx.doi.org/10.13005/ojc/320429

(Received: March 14, 2016; Accepted: June 17, 2016)

\begin{abstract}
The Phosphorus production is associated with the formation of technogenic wastes, such as phosphorus slag, boiler dust and gas emissions. Phosphorus sludge and boiler dust are a valuable secondary raw materials for the production of phosphate fertilizers. However, the reasonable and practically implemented recycling technologies of wastes into fertilizing products are still absent. In this regard, the search for new possibilities of recycling of large tonnage phosphorus-containing secondary raw materials is an important task. In this paper, mixture of phosphorus sludge, boiler dust, ammonium sulphate and humic acid was used for obtaining the fertilizer of type of ammonium phosphate. Technological conditions and basic indicators were identified for the proposed process.
\end{abstract}

Keywords: Phosphoric sludge, Toxic dust, Humic acid, Ammonium sulphate, Ammophos, superphosphate.

\section{INTRODUCTION}

According to the development strategy of "Kazakhstan - 2030", à special attention in the development of the chemical industry is paid to complex processing of technogenic wastes and attraction of substandard mineral resources into production'.
Modern production of phosphorus is a product in widely demand both in Kazakhstan and abroad are caused by the formation of technogenic wastes in the form of slag, ferrophosphorus, phosphoric sludge and toxic dust. At present, as a result of the reductive electrosmelting of phosphorite raw materials in one only the New Jambul phosphoric factory, about $140-160 \mathrm{~kg}$ of toxic dust is formed by 1 ton of production of yellow phosphorus, which 
as a suspension - toxic milk is discharged into evaporation basins ${ }^{2}$. Within territory of the former Shymkent phosphorus plant has accumulated more than 500 thousand tons of phosphoric sludge, which by their chemical and granulometric composition is characterized by complex inclusions of mineral components of the charge and products of recycling ${ }^{3}$.

Analysis of known literature data shows that these kinds of technogenic wastes are sufficiently valuable secondary raw materials for the production of phosphorus and complex phosphorus-potassium containing mixed fertilizers. The methods and technology of obtaining complex mineral fertilizers - superphosphate, double superphosphate, urea and ammonia fertilizer (UAF), monoammonium phosphate (MAPh), ammophos -based technogenic wastes containing phosphorus are known, modes of production were developed and the main characteristics of the final product were determined ${ }^{2-8}$.

There are works deals with kinetic studies of phosphorus compounds ${ }^{9-10}$. In the work $^{9}$ the kinetic studies have been made for synthesis of stable phosphorus ylids in the presence of different $\mathrm{NH}$-acids, such as Imidazole, 2-Methylimidazole or 4-Methylimidazole (as a protic/ nucleophilic reagent). At different temperature range studied, the

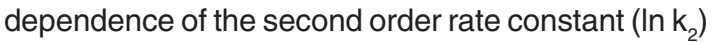
and $\left(\operatorname{In~} \mathrm{k}_{2} / \mathrm{T}\right)$ on reciprocal temperature was in a good agreement with Arrhenius and Eyring equations. This provided the relevant plots to calculate the activation parameters (Ea, $\Delta \mathrm{H}^{\#}, \Delta \mathrm{S}^{\#}$ and $\Delta \mathrm{G}^{\#}$ ) of all reactions. Furthermore, useful information were obtained from studies of the effect of solvent, structure of reactants (dialkyl acetylenedicarboxylates) and also concentration of reactants on the reaction rates. Proposed mechanism was confirmed according to the obtained results and steady state approximation, first and third steps $\left(k_{2}\right.$ and $\left.k_{3}\right)$ of all reactions was recognized as a rate determining and fast steps, respectively on the basis of experimental data.

In next work ${ }^{10}$ the importance of phosphate solubilization by microorganisms is well established in agriculture and dephosphorization of mineral ores. Ten species of Penicillium inhabiting the soils of Pachmarhi hills (1108-1287m above $\mathrm{msl}$ ) have been tested for their capacity of Phosphate solubilization using two samples of rock Phosphate and three of iron ores. The rock phosphate was solubilized up to $61.6 \%$ gm biomass in 10 days and the Phosphorus content of the iron ores was reduced up to $47.6 \%$ gm biomass. It was also evidenced that Phosphate solubilization potential of these Penicillia was related with their microhabitate where soluble Phosphate is scarcely available.

However, nowadays, fully substantiated technologies for processing wastes containing phosphorus into the demanded phosphorus, nitrogen, potassium containing products are still not developed. And so the known technological solutions have not found a full-scale practical application. In this regard, the search for new possibilities of recycling of large tonnage secondary raw materials containing phosphorus is still relevant.

Agricultural structures of the southern region, involved by cultivation of fruit and vegetable crops, in great need of complex nitrogen-, phosphorusand potassium-containing fertilizers. Ammophos occupies a special place among the similar and the most demanded complex fertilizers, which is a concentrated nonballast fertilizer with two nutrients in soluble form - nitrogen and phosphorus.

A widely demanded complicated complex NP fertilizer - ammophos is characterized by the content of the main component - monoammonium phosphate $\mathrm{NH}_{4} \mathrm{H}_{2} \mathrm{PO}_{4}$ with an admixture (10\%) of diammonium phosphate $\left(\mathrm{NH}_{4}\right)_{2} \mathrm{HPO}_{4}$. Production of ammophos by traditional technology envisages the decomposition of phosphates in excess, generated from them as the extraction phosphoric acid, subsequent ammoniation of an acidic phosphate suspension, its further evaporation, granulation and drying the evaporated mass ${ }^{11}$.

\section{MATERIAL AND METHODS}

For conducting laboratory researches by the establishment of physical and chemical characteristics of obtaining complex phosphorusnitrogen containing fertilizers, phosphoric sludge was collected from the different levels of sludge collectors of LLP "Kaynar". Toxic dust was taken from collections of toxic milk of the New Zhambyl 
phosphate plants. The selected samples were dried at a temperature of $60-80^{\circ} \mathrm{C}$ and sieved through a vibrating grid according to State Standard of 2156082 "Mineral fertilizers. Method for determination of granulometric composition" using a vibrating sieve screen of "Analysette 3" of model PRO.

Material composition of phosphoric sludge and toxic milk was established by chemical method according to State Standards of: $3760-79,9264-$ 79, 9336-75, 3765-78, 3773-72, 4109-79, 6709-72, 4198-75, 4461-77, 3652-69, 4209-77, 5850-72, 4234-77, 4204-77, 3118-77, 10484-78, 4212-78, 25336-82, 1770-74, 20292-74, 4144-79, 18300-72, 24363-80, 10652-73, 10398-76, 12083-78, 4478-78, 199-78, 3117-78, 61-75, 25794-83, and others.

The mineralogical composition and microstructure of samples of phosphoric sludge and toxic dust were obtained by a scanning electron microscope JEOI of brand JSM6490 LV.

Under experimental conditions, a mixture of phosphorus sludge and toxic dust, which were taken in a weight ratio of $2 \backslash 1$ was subjected to the decomposition in an acidic medium, formed by an aqueous solutions of ammonium sulphate and humic acid. The duration of the decomposition process, at an optimum temperature of $60^{\circ} \mathrm{C}$ has made 60 minutes.

In contrast to the traditional method, for the production of ammophos, a mixture of phosphoric sludge, toxic dust, ammonium sulphate and humic acid were used by us at different ratio. Moreover, ammonium sulfate was used for increasing the nitrogen components in the composition of obtaining ammophos, and humic acid with $\mathrm{pH}=0.760$ was used as a substitute of sulphuric acid, nitric acid or phosphoric acids.

\section{RESULTS AND DISCUSSION}

It was established that the material composition of phosphoric sludge and toxic milk corresponds to the following content:

- In the composition of phosphoric sludge, \%: $\mathrm{P}_{2} \mathrm{O}_{5}$ total - 17,01, $\mathrm{K}_{2} \mathrm{O}-6,72, \mathrm{Na}_{2} \mathrm{O}-0,41, \mathrm{SiO}_{2}-$ 45,38, $\mathrm{CaO}-13,74, \mathrm{MgO}-4,16, \mathrm{Al}_{2} \mathrm{O}_{3}-1,08, \mathrm{Fe}_{2} \mathrm{O}_{3}$ - 0,81, C - 5,91, S - 0,40;
- In the composition of toxic dust, \%: $\mathrm{P}_{2} \mathrm{O}_{5}$ tot. - 23,05, $\mathrm{K}_{2} \mathrm{O}-7,05, \mathrm{Na}_{2} \mathrm{O}-0,55, \mathrm{SiO}_{2}-25,08$, $\mathrm{CaO}-8,99, \mathrm{MgO}-1,29, \mathrm{Al}_{2} \mathrm{O}_{3}-2,66, \tilde{\mathrm{N}}-22,34, \mathrm{~S}-$ 0,36 .

The results, obtained by the scanning electron microscope, showed that minerals - calcium silicates, diopside and potassium aluminosilicates with inclusions of phosphate compounds of calcium predominate in phosphoric sludge and toxic dust ${ }^{8}$.

The chemistry of the decomposition process of a mixture of phosphorus sludge and toxic dust in an acidic medium of aqueous mixture of ammonium sulphate and humic acid may be described by the following equation:

$$
\begin{aligned}
& \mathrm{Ca}_{5}\left(\mathrm{PO}_{4}\right)_{3} \mathrm{~F}+8 \text { humic acid }+2\left(\mathrm{NH}_{4}\right)_{2} \mathrm{SO}_{4} \\
= & 2 \mathrm{CaSO}_{4}+4 \mathrm{NH}_{4}(\text { humic acid })++\mathrm{H}_{3} \mathrm{PO}_{4}+
\end{aligned}
$$
$2 \tilde{N}$ à(humic acid) $)_{2}+\mathrm{Ca}\left(\mathrm{H}_{2} \mathrm{PO}_{4}\right)_{2}+\mathrm{HF}$

After decomposition a mixture was subjected to filtration. It has been established that the obtained liquid phase - the filtrate has a density of 1,08 and $\mathrm{a} \mathrm{pH}=3.5$. This indicates that filtrate is the phosphoric acid of concentration of $14,60 \%$.

The obtained phosphoric acid was ammoniated by $25 \%$ ammonia water up to $\mathrm{pH}=6.0$.

The process of neutralization of phosphoric acid with ammonia water can be described by known reactions of following types:

$$
\begin{aligned}
& \mathrm{H}_{3} \mathrm{PO}_{4 \text { (liq) }}+\mathrm{NH}_{4} \mathrm{OH}_{\text {(liq) }}=\mathrm{NH}_{4} \mathrm{H}_{2} \mathrm{PO}_{4}+\mathrm{H}_{2} \mathrm{O} \\
& \mathrm{H}_{3} \mathrm{PO}_{4 \text { (liq) }}+2 \mathrm{NH}_{4} \mathrm{OH}_{\text {(liq) }}=\left(\mathrm{NH}_{4}\right)_{2} \mathrm{HPO}_{4}+2 \mathrm{H}_{2} \mathrm{O}
\end{aligned}
$$

Ammoniation process of filtrate phosphoric acid with ammonia water was carried out up to achieve of the final $\mathrm{pH}=6.0$.

The obtained neutralized solution was subjected to drying in a drying oven at $105^{\circ} \mathrm{C}$ until the complete crystallization of a mixture of monoammonium phosphate and diammonium phosphate. As a result of drying, a white powder with high water solubility was obtained. The obtained 
Table 1: Results of research of the decomposition process of phosphorus sludge and toxic dust mixture in an acidic medium of aqueous solutions of ammonium sulphate and humic acid

\begin{tabular}{|c|c|c|c|c|c|c|c|c|c|c|c|c|c|}
\hline 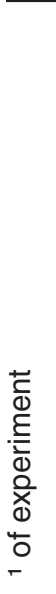 & 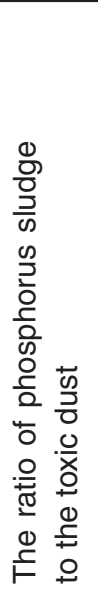 & 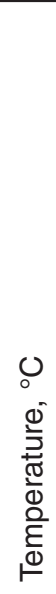 & 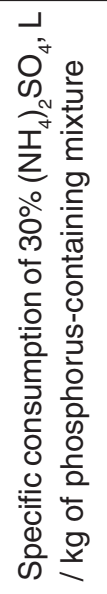 & 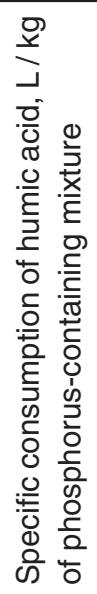 & 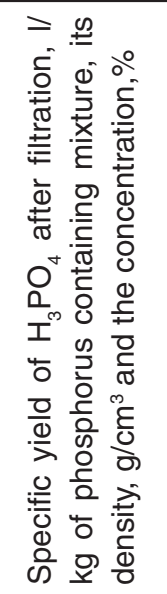 & 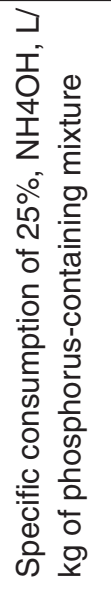 & 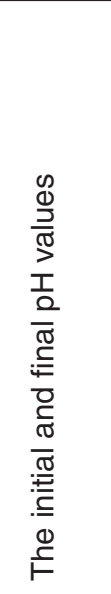 & 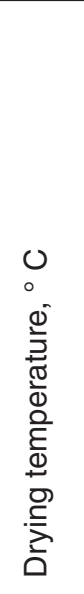 & 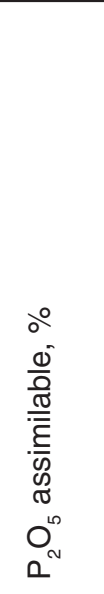 & 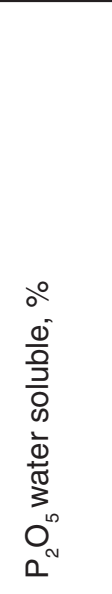 & 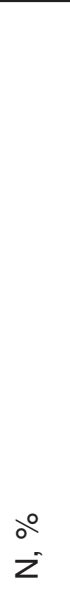 & 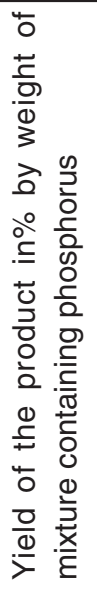 & 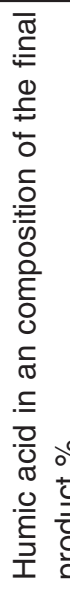 \\
\hline 1 & $2 \backslash 1$ & 60 & 0,15 & 0,10 & $\begin{array}{l}0,60 d=1 \\
1 c=17,87\end{array}$ & 0,060 & $\begin{array}{l}3 \text { up } \\
\text { to } 6\end{array}$ & 105 & 31,20 & 18,00 & 10 & 10 & \\
\hline 2 & 2\1 & 60 & 0,15 & 0,15 & $\begin{array}{c}0,80 d=1, \\
08 c=14,60\end{array}$ & 0,040 & $\begin{array}{l}3,5 \text { up } \\
\text { to } 6,0\end{array}$ & 105 & 33,75 & 20,10 & 10 & 10 & 1 \\
\hline 3 & $2 \backslash 1$ & 60 & 0,15 & 0,15 & $\begin{array}{l}1,00 d=1 \\
04 c=8,9\end{array}$ & 0,025 & $\begin{array}{l}3,7 \text { up } \\
\text { to } 6,0\end{array}$ & 105 & 31,75 & 15,62 & 10 & 10 & 1 \\
\hline 4 & $2 \backslash 1$ & 60 & 0,15 & 0,20 & $\begin{array}{c}0,60 d=1, \\
08 c=14,60\end{array}$ & 0,032 & $\begin{array}{l}3,2 \text { up } \\
\text { to } 6,0\end{array}$ & 105 & 36,50 & 30,60 & 10 & 10 & 1 \\
\hline 5 & $2 \backslash 1$ & 60 & 0,15 & 0,25 & $\begin{array}{c}0,80 d=1, \\
06 c=11,19\end{array}$ & 0,022 & $\begin{array}{l}3,5 \text { up } \\
\text { to } 6,0\end{array}$ & 105 & 32,25 & 22,50 & 8 & 10 & 1 \\
\hline
\end{tabular}

- $\mathrm{P}_{2} \mathrm{O}_{5}$ assimilable, $\% \mathrm{P}_{2} \mathrm{O}_{5}$ water soluble, $\% \quad \square \mathrm{N}, \%$

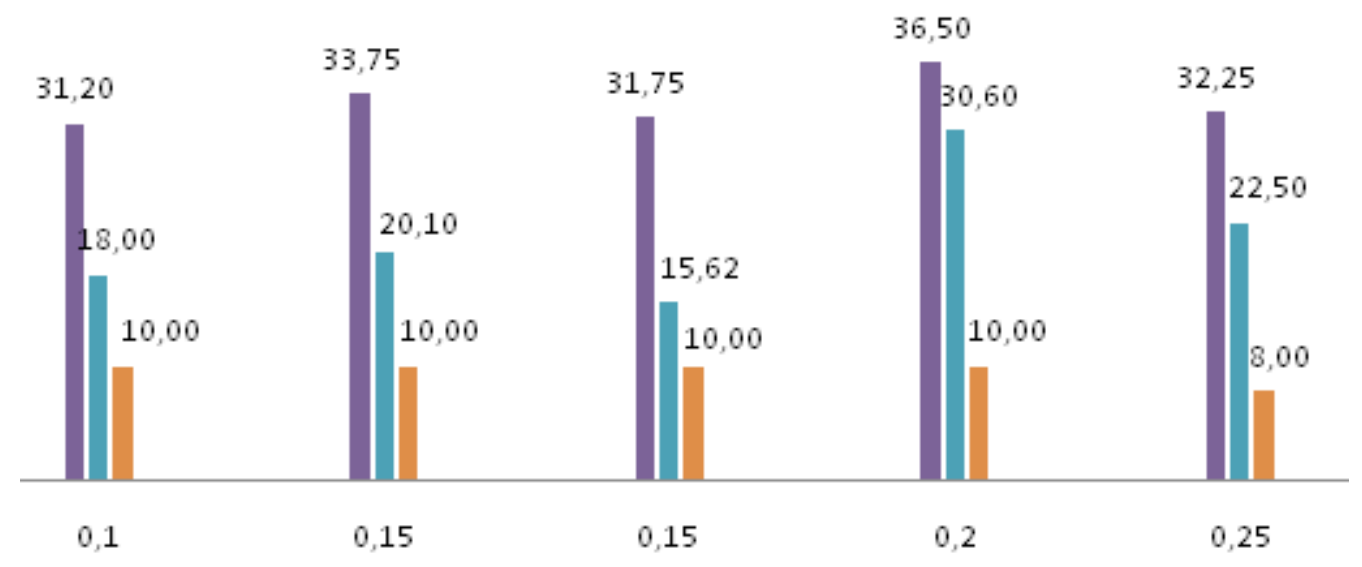

Specific consumption of humic acid, $L / \mathbf{k g}$ phosphorus containing mixture

Fig. 1: Dependence of the content of $\mathrm{P}_{2} \mathrm{O}_{5 \text { (assimilable) }}, \mathrm{P}_{2} \mathrm{O}_{5 \text { (water soluble) }}$ and nitrogen (in \%) in the final product from the specific consumption of humic acid, L/kg 
product is analyzed for content of digestible and water soluble of $\mathrm{P}_{2} \mathrm{O}_{5}$, ammonia and nitrogen.

The accepted ratio of phosphorus sludge to the toxic dust, temperature mode of their decomposition process in an acidic medium, expenditure indices of $30 \%$ solutions of ammonium sulphate and humic acid, ammoniation process conditions, and final product characteristics are given in Table 1.
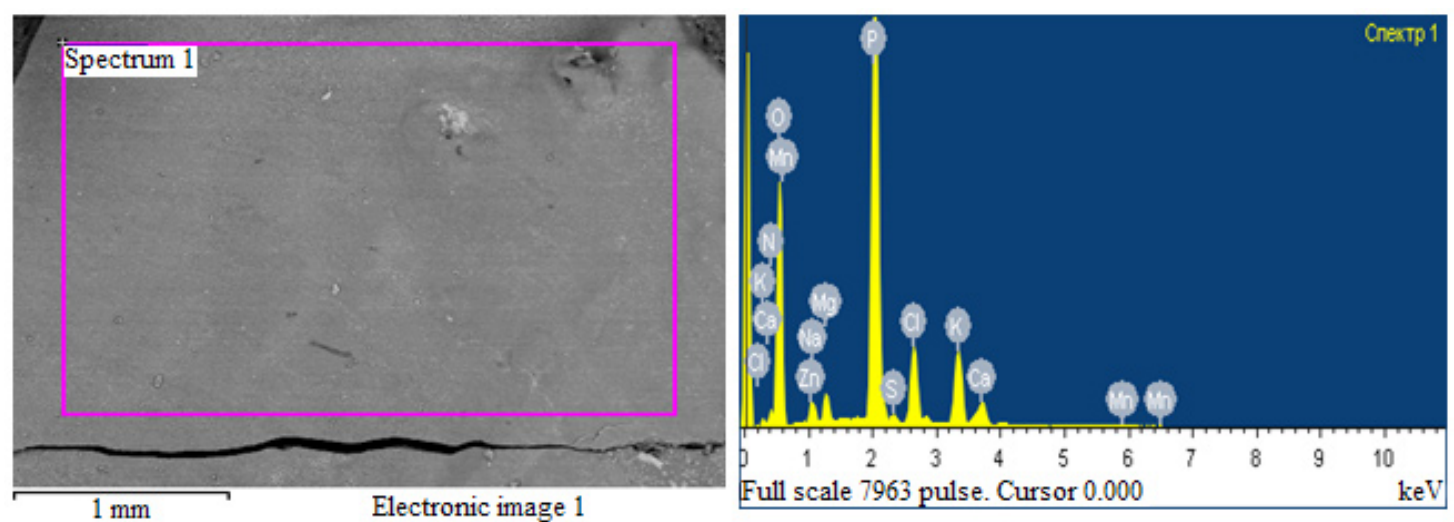

Fig. 2: Microscopic photograph of complex mineral fertilizers

Table 2: Element wise composition of complex mineral fertilizers

\begin{tabular}{lcc}
\hline $\begin{array}{c}\text { Element } \\
\text { composition, } \\
\%\end{array}$ & $\begin{array}{c}\text { Weight } \\
\text { composition, } \\
\text { in terms of } \\
\text { oxides, \% }\end{array}$ \\
\hline $\mathrm{N}$ & 11.68 & 11,68 \\
$\mathrm{O}$ & 48.81 & - \\
$\mathrm{Na}$ & 1.92 & 2,59 \\
$\mathrm{Mg}$ & 1.60 & 2,65 \\
$\mathrm{P}$ & 23.38 & 53,56 \\
$\mathrm{~S}$ & 0.61 & 1,31 \\
$\mathrm{Cl}$ & 3.84 & - \\
$\mathrm{K}$ & 5.84 & 7,03 \\
$\mathrm{Ca}$ & 1.84 & 2,57 \\
$\mathrm{Mn}$ & 0.18 & 0,23 \\
$\mathrm{Zn}$ & 0.27 & 0,33 \\
\hline
\end{tabular}

Analysis of the results of Table 1 shows that the greatest indicators by $\mathrm{P}_{2} \mathrm{O}_{5(\text { assimilable) }}$ and $\mathrm{P}_{2} \mathrm{O}_{5 \text { (water }}$ soluble) at a maximum nitrogen content in the final product are observed in experiment 4 . At the same time as seen in Figure 1, the maximum content of $\mathrm{P}_{2} \mathrm{O}_{5 \text { (assimilable) }}, \mathrm{P}_{2} \mathrm{O}_{5 \text { (water soluble) }}$ and nitrogen in the final product is observed at specific consumption of humic acid of 0,20 liters per kilogram of phosphorus sludge and toxic dust mixture.
Table 3: Element wise composition of dry residue, obtained after filtration

\begin{tabular}{lcc}
\hline Element & $\begin{array}{c}\text { Weight } \\
\text { composition, } \\
\%\end{array}$ & $\begin{array}{c}\text { Weight } \\
\text { composition, } \\
\text { in terms } \\
\text { of oxides, \% }\end{array}$ \\
\hline $\mathrm{C}$ & 12.73 & 12,73 \\
$\mathrm{O}$ & 39.74 & - \\
$\mathrm{F}$ & 5,3 & 5,30 \\
$\mathrm{Na}$ & 0.41 & 0,55 \\
$\mathrm{Mg}$ & 1.18 & 1,95 \\
$\mathrm{Al}$ & 1.28 & 2,42 \\
$\mathrm{Si}$ & 16.18 & 34,60 \\
$\mathrm{P}$ & 5.81 & 13,31 \\
$\mathrm{~S}$ & 0.87 & 2,18 \\
$\mathrm{Cl}$ & 0.19 & - \\
$\mathrm{K}$ & 2.77 & 3,34 \\
$\mathrm{Ca}$ & 8.73 & 12,21 \\
$\mathrm{Mn}$ & 0.11 & 0,14 \\
$\mathrm{Fe}$ & 0.53 & 0,76 \\
$\mathrm{Zn}$ & 0.31 & 0,39 \\
& & \\
\hline & & \\
\hline & &
\end{tabular}


Table 4: Main indicators of dry residue, obtained after filtration

$\begin{array}{lc}\text { Indicators of dry residue } & \\ \mathrm{P}_{2} \mathrm{O}_{5} \text { assimilable, \% } & 13,25 \\ \mathrm{P}_{2} \mathrm{O}_{5} \text { water soluble, \% } & 4,75 \\ \mathrm{~N}, \% & 4,75 \\ \text { Product yield, kg/kg of } & 0,85 \\ \text { initial mixture containing phosphorus } & \\ \text { Strength of granules } \mathrm{kg} / \mathrm{cm}^{2} & 3,40 \\ \text { Humic acid, \% } & 7-10 \\ \mathrm{pH} \text { value } & 5,20\end{array}$

The physico-chemical features were studied, obtained on the basis of phosphoric sludge and toxic dust, complex nitrogen-phosphoruscontaining mineral fertilizer. Using a scanning electron microscope, elementwise and mineralogical analysis of its composition were carried out. Results of microscopic studies ${ }^{12}$, give the opportunity to obtain an image of surface of the investigated samples and the spectra of the individual points, with the representation of elementwise and percentage composition, as well as the diffraction peaks of

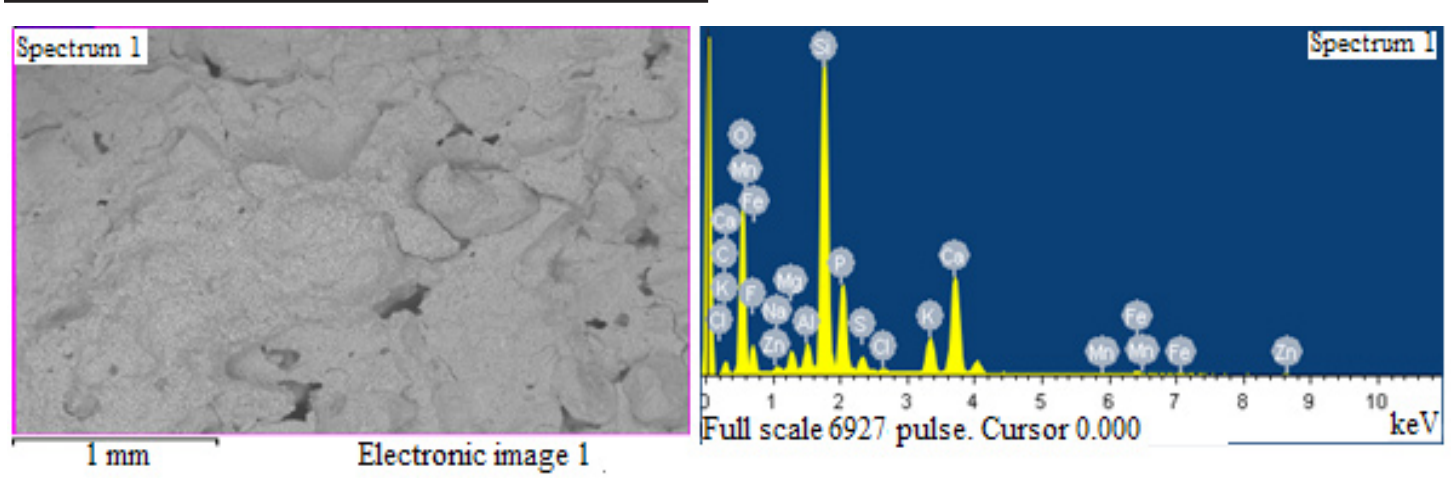

Fig. 3: Microscopic photograph of dry residue, obtained after filtration

individual elements with high spatial resolution and the required depth of field of view.

Microscopic photograph and the results of elemental analysis of complex mineral fertilizers are presented in Figure 2 and Table 2.

Figure 2 shows that the surface of the analyzed microsection is characterized by high light transmitting capacity. The results of the elemental and weight analysis of complex mineral fertilizer (Table 2 ), as well as the intensity of the diffraction peaks testify in favor reality of flow, given above reactions of major stages of the process for producing ammophos by the developed technique. It follows from Table 2, the basic constituents of the minerals of obtained product is a compound of $\mathrm{P}_{2} \mathrm{O}_{5}$ in the complex with nitro compounds.

As the local inclusions, $\mathrm{K}_{2} \mathrm{O}$ (up to $7,03 \%$ ), $\mathrm{NaNO}_{3}$ (up to 2,59\%) and impurities of magnesium sulfate and calcium in the range of $2,57-2,65 \%$ are also present. The obtained product by content of phosphoric anhydride (53,56\%) and nitrogen $(11,68 \%)$ corresponds ammophos of State Standard 18918-85 of mark A with the impurities of zinc ${ }^{13}$.

Analysis of data of Table 3 about the elementwise composition of dry remainder, obtained after filtration, shows the presence of a carbon of $12,73 \%$, Si $-16.18 \%$, (in terms of $\mathrm{SiO}_{2}-34,60 \%$ ), a fluorine $-5,30 \%$, calcium $-8,73 \%$ (in terms of $\mathrm{CaO}$ $12,21 \%$ ) and phosphorus $-5,81 \%$ (in terms of $\mathrm{P}_{2} \mathrm{O}_{5}$ - 13,31\%) in it.

Results of chemical analysis of dry residue (Table 4) indicate that it contains $\mathrm{P}_{2} \mathrm{O}_{5 \text { (assimilable) }}$ of $13,25 \%, \mathrm{P}_{2} \mathrm{O}_{5 \text { (water soluble) }}-4.75 \%$ and $\mathrm{N}-4,75 \%$, as well as humic acid of $7-10 \%$.

The above mentioned data allows to judge about the possibility of using the dry residue as the ammoniated superphosphate. It has been established that this product is also characterized by 
a high solubility in water. For example, its granules of diameter of 5-8 $\mathrm{mm}$ dissolve in water for 3-5 seconds.

\section{CONCLUSION}

The results of the conducting investigations suggest the following conclusions:

- $\quad$ Based on the mixture of phosphoric sludge and toxic dust at a ratio of $2 \backslash 1$ and during the use for their decomposition of $30 \%$ aqueous solution of ammonium sulphate and humic acid, in a temperature condition of $60^{\circ} \mathrm{C}$ and at an optimal duration of the process of 60 minutes it is possible to obtain the productional ammophos with the content of assimilable phosphoric anhydride - 53,56\% nitrogen $-11,68 \%$ zinc - $0,33 \%$, as well as humic acid - 10-15\%;
- $\quad$ Dry residue, obtained after filtration stages, in the composition has: phosphorus of $5,81 \%$ (in terms of $\mathrm{P}_{2} \mathrm{O}_{5}-13,31 \%$, including $\mathrm{P}_{2} \mathrm{O}_{5}$ assim. $13,25 \%, \mathrm{P}_{2} \mathrm{O}_{5}$ water sol. - 4,75\%) nitrogen - $4,75 \%$, humic acid of $7-10 \%$, which corresponds to the composition of ammoniated superphosphate;

- Initial humic acid used in the process of decomposition of phosphate secondary raw materials, is a highly efficient substitute for expensive and aggressive mineral acids such as sulfuric and nitric. Residual humic acid in the composition of ammophos and ammoniated superphosphate will serve as organic and mineral supplements, contributing the improvement of soil structure, and will show the quality of the protective composition of plants against pests and diseases.

\section{REFERENCES}

1. Strategy of development of "Kazakhstan2030"

2. Electronic resource: http://www.inform.kz/rus/ article/228083

3. Aldashov, B.A.; Lisitsa, V.I. Disposal of Karatau phosphorite wastes - the path to a competitive economy and improve the environment, Almaty Gylym, 2007, 428.

4. Postnik, N.N. Thermal phosphoric acid. Moscow, Chemistry, 1972, 308.

5. Dzhusipbekov, U. ZH.; Chernjakova, R.M.; Oshakbayev, M.T.; Nurgaliyeva, G.O. Processing of substandard phosphorites of Karatau and technogenic wastes on fertilizers, Almaty, Gylym, 2000132.

6. Batkaev, R.I. Development of technology for obtaining marketable products from technogenic wastes of production of phosphorus: Doctoral thesis, M. Auezov South Kazakhstan State University, Shymkent, 2010.
7. Nazarbek, U.B., Besterekov, U., Nazarbekova, S.P. and Bolysbek A.A., Orient. J. Chem., 2015, 31(1), 215-221

8. Nazarbek, U.B., Besterekov, U., Petropavlovsky I.A., Nazarbekova S.P. and Beisenbayev, O.K., Orient. J. Chem., 2015, 31( 3), 1409-1416

9. Zakarianezhad, M.; Habibi-Khorassani S. M; Maghsoodlou M.T. and Makiabadi B., Orient. J. Chem., 2012, 28( 3), 1259-1269

10. Sharma Kavita. Orient. J. Chem., 2011, 27(1), 101-103

11. Posin, M.E. Technology of mineral fertilizers, Textbook. Leningrad, Chemistry, 1989, 352.

12. Reed, S.Dzh.B. Electron probe microanalysis and scanning electron microscopy in geology, Moscow, Technosphere, 2008, 232.

13. Mineral Fertilizers. Test methods: Collection of State Standards. Moscow, IEC Publisher standards, 2003. 